LA W RENCE LIVERMORE N A TIONAL LABORATORY

Possible Methods to Estimate Core Location in a Beyond-Design-Basis Accident at a GE BWR with a Mark I Containment Stucture

S. Walston, M. Rowland, K. Campbell

July 29, 2011 
This document was prepared as an account of work sponsored by an agency of the United States government. Neither the United States government nor Lawrence Livermore National Security, LLC, nor any of their employees makes any warranty, expressed or implied, or assumes any legal liability or responsibility for the accuracy, completeness, or usefulness of any information, apparatus, product, or process disclosed, or represents that its use would not infringe privately owned rights. Reference herein to any specific commercial product, process, or service by trade name, trademark, manufacturer, or otherwise does not necessarily constitute or imply its endorsement, recommendation, or favoring by the United States government or Lawrence Livermore National Security, LLC. The views and opinions of authors expressed herein do not necessarily state or reflect those of the United States government or Lawrence Livermore National Security, LLC, and shall not be used for advertising or product endorsement purposes.

This work performed under the auspices of the U.S. Department of Energy by Lawrence Livermore National Laboratory under Contract DE-AC52-07NA27344. 


\title{
Possible Methods to Estimate Core Location in a Beyond-Design-Basis Accident at a GE BWR with a Mark I Containment Structure
}

\author{
Sean Walston* Mark Rowland $†$ Kirk Campbell ${ }^{\ddagger}$ \\ Lawrence Livermore National Laboratory
}

April 26, 2011

\begin{abstract}
It is difficult to track to the location of a melted core in a GE BWR with Mark I containment during a beyond-design-basis accident. The Cooper Nuclear Station provided a baseline of normal material distributions and shielding configurations for the GE BWR with Mark I containment. Starting with source terms for a design-basis accident, methods and remote observation points were investigated to allow tracking of a melted core during a beyond-design-basis accident.
\end{abstract}

\section{LLNL-TR-XXXxxx}

\footnotetext{
*Tel.: 925-423-7364. E-mail: walston2@llnl.gov

†Tel.: 925-423-2003. E-mail: rowland3@llnl.gov

‡Tel.: 925-423-1353. E-mail: campbell76@llnl.gov
} 


\section{Executive Summary}

The design of the GE BWR with Mark-I containment highlights an amazing poverty of expectations regarding a common mode failure of all reactor core cooling systems resulting in a beyond-design-basis accident from the simple loss of electric power. This design is shown in Figure 1. The station blackout accident scenario has been consistently identified as the leading contributor to calculated probabilities for core damage [1].

While NRC-approved models and calculations provide guidance for indirect methods to assess core damage during a beyond-design-basis loss-of-coolant accident (LOCA), there appears to be no established method to track the location of the core directly should the LOCA include a degree of fuel melt.

We came to the conclusion that - starting with detailed calculations which estimate the release and movement of gaseous and soluble fission products from the fuel - selected dose readings in specific rooms of the reactor building should allow the location of the core to be verified.

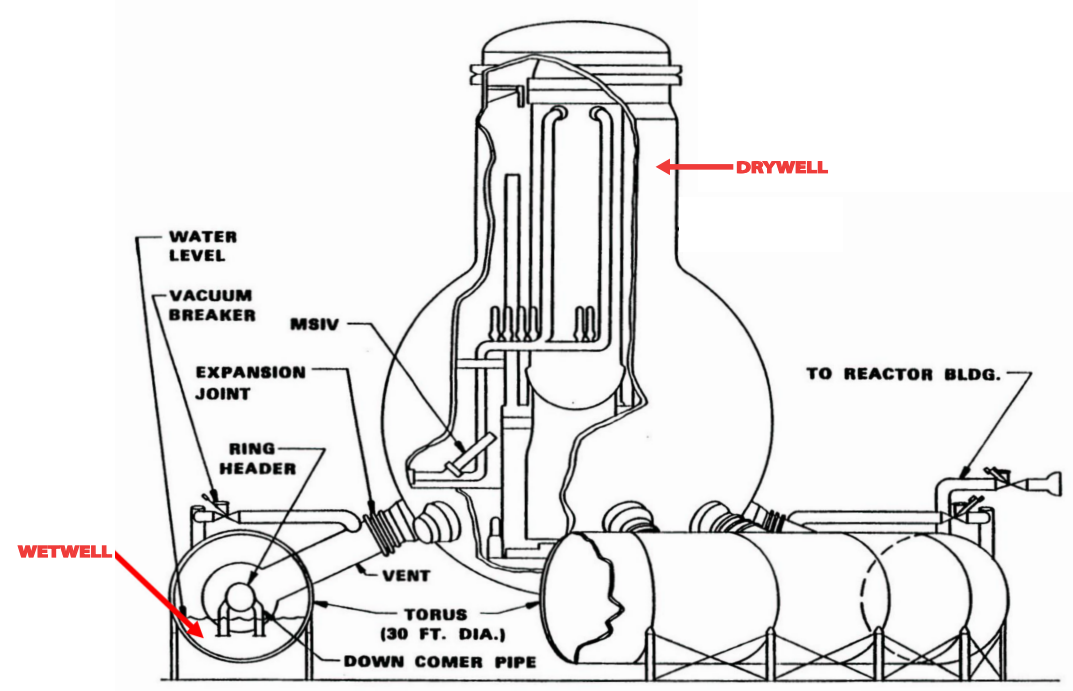

Figure 1: General layout of the GE BWR with Mark I containment.

\section{Key Events During a LOCA}

Within a day after shutdown, decay heat produces $\sim 10 \mathrm{MW}$. Between 1 and 2 months post shut-down, this drops to $\sim$ a few MW.

A total loss of electrical power will cause the failure of all core cooling systems except for the reactor core isolation cooling (RCIC). The reactor core isolation 
pump uses steam from the reactor vessel to drive a turbine. The steam is then condensed in the wet well. The turbine in turn drives a pump to move water from the wet well back into the reactor vessel. The reactor core isolation cooling requires at a minimum both electrical power from the batteries and a wet well temperature $<100^{\circ} \mathrm{C}$. Absent some method of heat removal from the wet well, the reactor core isolation pump cannot cool the reactor indefinitely.

Upon failure of the reactor core isolation pump, the temperature and pressure within the reactor vessel will rise rapidly. At $\gtrsim 1000$ psi, the steam relief valves on the reactor vessel will discharge excess steam into the wet well - or torus - of the primary containment structure. After the pressure has equilibrated, the steam relief valve re-closes, causing the pressure to rise once again. This cycle could repeat if heat is not removed by other means.

The loss of water into the wet well will eventually cause the core to become uncovered. The time from the failure of the reactor core isolation pump to the top of the core becoming uncovered is expected to be $\lesssim 10$ hours. As the core becomes uncovered, its temperature will inevitably rise above $\sim 1000^{\circ} \mathrm{C}$. Fission products - most notably noble gasses, halogens, and cesium — will be released from the fuel pin gaps as the cladding begins to rupture. Three Mile Island experienced cladding failure 34 minutes after the core initially became uncovered.

When the temperature of the zirconium fuel cladding rises above $1200^{\circ} \mathrm{C}$, the zirconium in the cladding starts to react with the steam through the reaction

$$
\mathrm{Zr}+2 \mathrm{H}_{2} \mathrm{O} \rightarrow \mathrm{ZrO}_{2}+2 \mathrm{H}_{2}
$$

This exothermic reaction will further heat the core. Note that a byproduct of this reaction is hydrogen gas. This hydrogen, along with fission product noble gasses, halogens, and cesium, will be carried to the torus through the reactor vessel steam relief valve.

As the temperature of the core continues to rise, the fuel will begin to melt. The first stage of core relocation is to the fuel support plate. The liquified fuel then dissolves into the melted components and if heat is not removed, a slump of molten core will fall to the bottom of the reactor vessel and eventually melt through to fall into the bottom of the drywell of the primary containment structure. This entire process may be expected to take mere hours unless it is arrested by a restoration of cooling water to the core.

\section{Indirect Indications of Core Damage}

Normal dose readings inside the reactor building are $\sim 1 \mathrm{mrem} / \mathrm{hr}$ whether shutdown or running. In the drywell during shutdown, the dose is typically $\sim 50 \mathrm{mR} / \mathrm{hr}$; during normal running, the dose is $\sim 1 \mathrm{R} / \mathrm{hr}$. In the turbine hall during shutdown, the dose is $\sim 1 \mathrm{mR} / \mathrm{hr}$; when running, the dose is $\sim 1 \mathrm{R} / \mathrm{hr}$ [2]. The fission product inventory at the time of reactor shutdown assuming three years of continuous operations at $102 \%$ power is listed in table 1 . 


\begin{tabular}{|l|c|r|}
\hline Chemical Group & Elements & Inventory (Ci) \\
\hline \hline Noble Gasses & Kr, Xe & $2.40 \times 10^{8}$ \\
Halogens & $\mathrm{I}$ & $5.52 \times 10^{8}$ \\
Alkali Metals & $\mathrm{Cs}$ & $1.37 \times 10^{8}$ \\
Tellurium & $\mathrm{Te}$ & $0.90 \times 10^{8}$ \\
Nobel Metals & $\mathrm{Mo}, \mathrm{Ru}$ & $2.20 \times 10^{8}$ \\
Alkaline Earths & $\mathrm{Sr}, \mathrm{Ba}$ & $2.68 \times 10^{8}$ \\
Rare Earths & $\mathrm{Y}, \mathrm{La}, \mathrm{Ce}$ & $3.90 \times 10^{8}$ \\
Refractories & $\mathrm{Zr}$ & $2.13 \times 10^{8}$ \\
\hline \hline Total & & $21.10 \times 10^{8}$ \\
\hline
\end{tabular}

Table 1: Inventory of fission products at time of reactor shutdown assuming three years of continuous operations at $102 \%$ power [3].

NRC-approved models and calculations provide indications and extent of core damage as follows [3]:

1. The concentration of ${ }^{131} \mathrm{I}$ in the coolant is expected to correlate well with the degree of fuel melt:

- $\sim 10^{2} \mu \mathrm{Ci} / \mathrm{ml}$ correlates with a $\sim 1 \%$ fuel melt

- $\sim 10^{3} \mu \mathrm{Ci} / \mathrm{ml}$ correlates with a $\sim 10 \%$ fuel melt

- $\sim 10^{4} \mu \mathrm{Ci} / \mathrm{ml}$ correlates with a $\sim 100 \%$ fuel melt

2. The concentration of ${ }^{137} \mathrm{Cs}$ in the coolant is likewise expected to correlate well with the degree of fuel melt:

- $\sim 10^{1} \mu \mathrm{Ci} / \mathrm{ml}$ correlates with $\mathrm{a} \sim 1 \%$ fuel melt

- $\sim 10^{2} \mu \mathrm{Ci} / \mathrm{ml}$ correlates with a $\sim 10 \%$ fuel melt

- $\sim 10^{3} \mu \mathrm{Ci} / \mathrm{ml}$ correlates with a $\sim 100 \%$ fuel melt

3. High concentrations (relative to known historical concentrations) of any of the less volatile fission products are indicative of fuel melt. In particular:

- Alkaline earths including $\mathrm{Sr}$ and $\mathrm{Ba}$

- Noble metals including Ru, Rh, Pd, Mo, and Tc

- Rare earths including Y, La, Ce, Nd, Pr, Eu, Pm, and Sm

- Refractories including $\mathrm{Zr}$ and $\mathrm{Nb}$

- Transuranics including $\mathrm{Np}$ and $\mathrm{Pu}$

4. Hydrogen is an indication of core damage. During normal operations, the amount of dissolved hydrogen within the reactor coolant is negligible. The zirconium-steam reaction by comparison produces copious amounts of hydrogen: 
- At $\approx 5 \%$ Zr-steam reaction, likely cladding failure would result

- At $\approx 10 \%$ Zr-steam reaction, initial fuel melting may be exhibited

- At $\approx 20 \% \mathrm{Zr}$-steam reaction a possible uncoolable core may result

- At $\approx 30 \% \mathrm{Zr}$-steam reaction, possible reactor vessel melt-through may occur

5. Containment radiation monitors

- Drywell

- $1 \%$ fuel melt: $\sim 10^{4} \mathrm{R} / \mathrm{hr}$

- $10 \%$ fuel melt: $\sim 10^{5} \mathrm{R} / \mathrm{hr}$

- $100 \%$ fuel melt: $\sim 10^{6} \mathrm{R} / \mathrm{hr}$

- Torus

$-1 \%$ fuel melt: $\sim 5 \times 10^{3} \mathrm{R} / \mathrm{hr}$

- $10 \%$ fuel melt: $\sim 5 \times 10^{4} \mathrm{R} / \mathrm{hr}$

- $100 \%$ fuel melt: $\sim 5 \times 10^{5} \mathrm{R} / \mathrm{hr}$

\section{Direct Verification of Core Location}

Between 1-2 months post accident, models estimate the dose in the reactor building at ground level to average $\sim 10^{2} \mathrm{R} /$ hour (see Figure 2) [4]. These models assume that $100 \%$ of the core inventory of radioactive noble gases, $50 \%$ of the core inventory of radioactive halogens, and $1 \%$ of the core inventory of other radioactive isotopes have been released to the primary containment [5].

For a beyond-design-basis accident, there appears to be no established method to track the location of the fuel as it melts. The question is then how far has a molten core moved? The three possibilities are

1. Fuel support plate

2. Bottom of reactor vessel

3. Drywell of the primary containment structure

The Control Rod Drive (CRD) removal hatch, as indicated in Figure 2 and shown in Figure 3, provides a direct window to the bottom of the drywell and offers a possible method to establish whether or not the core has progressed to the drywell. The CRD removal hatch is designed to allow installation and removal of control rod drive mechanisms. The control rod drives are inserted into the bottom of the drywell via this hatch, oriented vertically, and then attached to the bottom of the reactor vessel and coupled to the actual control rods themselves.

At $2 \mathrm{MeV}$, the half-value thickness of concrete is $7 \mathrm{~cm}$. The 6' 2 " thick concrete comprising the drywell wall would reduce the radiation dose by $\sim 10^{8}$ compared with that inside the drywell. The dose emanating from the CRD 
removal hatch could be expected to be several orders of magnitude higher (depending on the thickness of the steel hatch itself) compared to that coming through the concrete walls of the drywell. If the core has come to rest at the bottom of the drywell, and the drywell is not flooded, there may be a significantly elevated neutron count rate emanating from the CRD removal hatch as well.

If the core has not melted through the bottom of the reactor vessel, the radiation emanating from the CRD removal hatch would be dominately from noble gasses, halogens, and cesium which have been released into the primary containment structure. If, however, the core has fallen to the bottom of the drywell, the dose through the CRD removal hatch could be expected to be an order of magnitude higher recalling that - after shutdown - noble gasses, halogens, and cesium account for $\sim 10^{9} \mathrm{Ci}$ while all other constituents amount to $\sim 10^{10} \mathrm{Ci}$.

\section{Achnowledgements}

The authors wish to thank Jeremy Bebb, Bob Bielke, John Martin, and Steve Nelson at the Cooper Nuclear Station for all their help and generous hospitality.

\section{References}

[1] S. A. Hodge, J.C. Cleveland, T. S. Kress, and M. Petek. Identification and Assessment of BWR In-Vessel Severe Accident Mitigation Strategies.

[2] Jeremy Bebb, private communication.

[3] Core Damage Assessment, Revision 23 via Bob Bielke, private communication.

[4] CNS Calculation NEDC 02-003 via Bob Bielke, private communication.

[5] CNS Calculation NEDC 01-065 via Bob Bielke, private communication. 


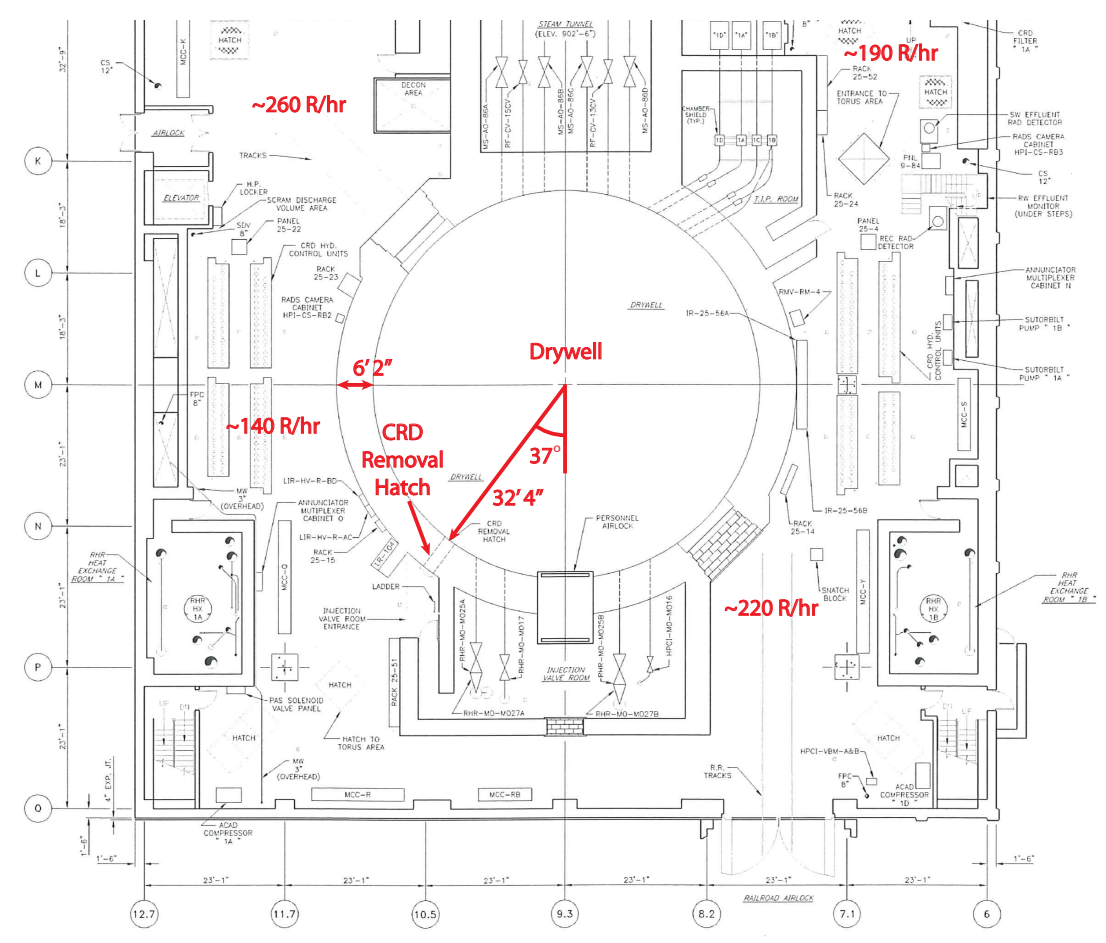

Figure 2: Plan view of the ground floor to the Cooper Nuclear Station with average expected dose rates between 30 and 60 days post-LOCA. These doses assume that $100 \%$ of the core inventory of radioactive noble gases, $50 \%$ of the core inventory of radioactive halogens, and $1 \%$ of the core inventory of other radioactive isotopes have been released to the primary containment. The control rod drive (CRD) removal hatch provides a line-of-sight access to the equipment handling platform above the bottom of the drywell. This platform is directly under the reactor vessel and is 6' 9" below ground-level. The radius of the drywell at this elevation is $32^{\prime} 4^{\prime \prime}$. The walls of the drywell are of concrete 6' 2 "' thick. 


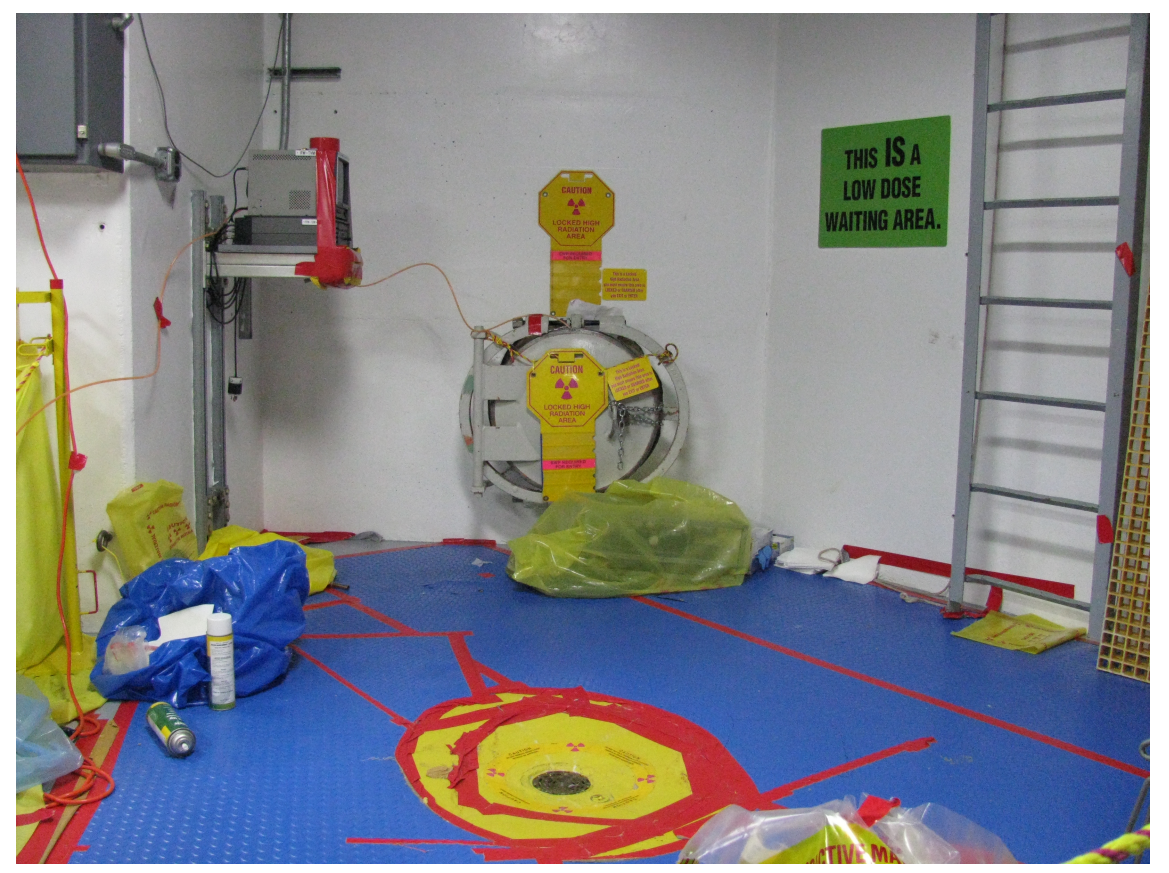

Figure 3: Photograph of the control rod drive (CRD) removal hatch. 